ON THE RECORD

(C) used to watch Doctor

Who and Star Trek, but

they went [politically

correct] - making

women commanders,

that sort of thing. I

stopped watching.)”

British television personality Patrick

Moore, who has presented a show

on astronomy since 1957, alienates a

large proportion of his audience.

(CI believe in evolution.

But I also believe, when

I hike the Grand Canyon

and see it at sunset, that the hand of God is there also.")

US presidential hopeful John McCain (Republican) tries not to alienate anyone at a recent debate. Three of his rivals for the nomination declared that they don't believe in evolution.

\title{
ZOO NEWS
}

\section{Crash and burn}

Wildlife workers in Florida say that the wildfires raging across the state are killing hundreds of yellow warblers (pictured). Clouds of smoke are causing the disorientated birds to drop out of

the sky or career into buildings.

\section{SCORECARD}

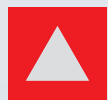

High ceilings Researchers at the University of

Minnesota claim that rooms with lofty ceilings encourage "freer, more abstract thinking", whereas more poky spaces activate more "confined concepts".

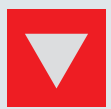

\section{Texan skies}

Plans for a 'body farm' to help forensic experts study decomposition have been shelved amid fears that the Texas State University facility would attract buzzards and endanger nearby planes.

Sources: $A B C, B B C$, Livescience.com, washingtonpost.com, Associated Press

\section{Applicants challenge male order at Howard Hughes}

The Howard Hughes Medical Institute (HHMI) is one of the wealthiest philanthropic organizations supporting biomedical research, but Dora Angelaki didn't want to become one of its investigators just for the money.

With funding from the National Institutes of Health (NIH) and NASA, her neurobiology lab at Washington University in St Louis, Missouri, is hardly starved for cash. What she wanted was to embark on riskier projects that would be difficult to sell to conservative, federal research agencies. So when her colleagues encouraged her to enter the HHMI competition, she was eager to give it a go.

Unfortunately, as Angelaki soon discovered, the competition is open only to academic researchers who have been running a lab for between four and

"The four-to-tenyear window works very strongly against women." ten years. Angelaki has been at it since November 1993. And even with the two extra years that the HHMI allows to compensate for the fact that she had two children during that time, Angelaki missed the window by 18 months.

Her exclusion highlights what critics claim is a persistent problem for women scientists trying to become an HHMI investigator. Some argue that the institute's nominating practices and restrictive time limits hinder such career development - issues that the HHMI itself has recognized and taken steps to correct. But questions persist as to whether these steps go far enough.

“They've taken a huge step forward," says Ben Barres, a neurobiologist at Stanford University in California. "But they still need to diversify their selection committees. And I think this four-to-ten-year window works very strongly against women."

As a result of changes put forward in 2005 by the institute's president, Thomas Cech, the current competition is the first in which individuals can directly apply to the HHMI, rather than having to be nominated by a university. This is intended to make the process more open to women, minority groups and young scientists.

Nevertheless, some researchers would like the HHMI to go further. Barres says it should extend its window of eligibility from 10 to 16 years, to lessen the disadvantage faced by women who have had children soon after becoming assistant professors. But HHMI spokeswoman Avice Meehan says that the 10-year limit is important to enable the institute to maintain a pool of early-career investigators. And, she adds, applicants for the investigator competition are

\section{Time runs short for HapMap}

Geneticists at the genomics meeting in Cold Spring Harbor, New York, last week celebrated the success of the International HapMap project - and predicted its eventual demise.

The project, unveiled in 2005, is a database of markers of genetic diversity called single nucleotide polymorphisms, or SNPs. By comparing HapMap data against SNPs from people with specific diseases, researchers hope to pinpoint the genetic glitches that underlie those diseases.

Many studies have now been published that have used data from the HapMap project, which aims to cut down the cost and effort involved in finding the genetic errors that lead to common disorders such as heart problems, mental illness and diabetes.

At the meeting, Peter Donnelly of the University of Oxford, UK, who is one of the investigators in the Wellcome Trust Case Control Consortium, presented findings from a major study the group conducted of seven common diseases in 16,179 participants. The study, expected to be published shortly, is perhaps the most ambitious trawl yet for common disease genes. And it did turn up possible genetic causes for some of the diseases, Donnelly said. Together with results from other 'genome-wide association studies', Donnelly's report had researchers toasting their successes, and hoping for more.

"For ten years, we have been predicting that genomewide association studies will work, and it is clear now that they do," says Ewan Birney, who runs the gene bank at the 
